\title{
Anesthetic Techniques for Urological Surgeries in Benue State University Teaching Hospital (BSUTH), Makurdi, Nigeria
}

\author{
M. E. Efu, E. I. Ogwuche, B. A. Ojo, B. A. Eke
}

\section{ABSTRACT}

Background: Urological surgery entails operating on the urinary system. Like every other surgery, they require anesthesia for the elimination of surgical pain. The organ to be operated as well as surgical approach determines the choice of anaesthesia used. This may be in the form of regional (including neuroaxial anesthesia) or general or even local anesthesia. This study was conducted to ascertain the anesthetic techniques employed for urological surgeries in the Benue State University Hospital (BSUTH), Makurdi, Nigeria.

Methodology: This was a three-year retrospective study carried out in BSUTH, Makurdi, Nigeria. A total of 125 case files of eligible patients were retrieved from the records department following approval of an application. Relevant information was extracted from the patients' folders and transferred into a prepared proforma. The data collected were analyzed using SPSS version 25 using simple statistics.

Results: The age group with the highest number is that between 61 and 70 years, recording $40(32.0 \%)$. The mean age was $54.0 \pm 20.4$ Males were a clear majority with 119 cases accounting for $95.2 \%$ while only 6 cases (4.8\%) involved females. The male to female ratio was 19.8:1. Most of the patients belonged to ASA II which recorded $70(56.0 \%)$. Of the total of 125 diagnoses made, cancer of the prostate $(\mathrm{CaP})$ was the highest with 63 (50.4\%). The most common surgical procedure was prostate biopsy which was undertaken 58 times accounting for $46.4 \%$ of the procedures. Caudal block was employed most with $59(47.2 \%)$. This was followed by Local infiltration with $30(\mathbf{2 4 . 0 \%})$. Eighty-eight patients had surgery on day case basis while 37 patients underwent surgery as in-patients representing $70.4 \%$ and $29.6 \%$ of the study group respectively.

Conclusion: Urological procedures are mostly infra-umbilical and are thus quite amenable to either regional or local anesthesia. This study has shown that caudal epidural block is the anesthetic technique of choice in urological surgery in this centre. Local anesthesia and sub-arachnoid block are next in that order. GA is not often employed. LA and regional techniques involve fewer disturbances to the respiratory system, and these were the anaesthetic methods mostly employed as established in this study.

Keywords: Anesthetic techniques, urological surgeries.

\section{INTRODUCTION}

Urological surgery entails operating on the urinary system. This includes structures such as the kidneys, ureters, urinary bladder, prostate gland, and the urethra. Like every other surgery, they require anesthesia for the elimination of surgical pain. Urological operations may be on day case basis or in-patient basis. They may be endoscopic or open. Also, these surgeries may be undertaken as emergencies or they may be done as electives. Most of the emergencies present at odd hours [1] when less experienced personnel are on ground and patients are not optimally prepared for the
Published Online: September 16, 2020

ISSN: $2593-8339$

DOI: $10.24018 /$ ejmed.2020.2.5.403

M. E. Efu*

Benue State University, Nigeria. (e-mail: enokelaefu@ gmail.com)

\section{E. I. Ogwuche}

Benue State University, Nigeria.

\section{B. A. Ojo}

Benue State University, Nigeria.

B. A. Eke

Benue State University, Nigeria.

*Corresponding Author operations as such, the outcome is poor with resultant increased morbidity and mortality [2]. Elective operations, on the other hand, are scheduled operations where patients are well prepared prior to surgery and as such have better outcome when compared to emergency operations where morbidity and mortality are higher [3].

These surgical approaches largely, determine the choice of anesthesia used. This may be in the form of regional (including neuroaxial anesthesia) or general or even local anesthesia. Neuroaxial anesthesia (NA) refers to the use of local anesthetic agents in the adjoining area of the spinal cord in order to eliminate the perception of painful stimuli 
[4]. General anesthesia (GA), on the other hand, refers to the use of drugs that lead to loss of consciousness and, consequently, to the eradication of the perception of painful stimuli [4]. Because many urological procedures are infra umbilical, they put the anesthetist at an advantage because not only is there less disruption to the respiratory function, but it is also possible to carry out most of these surgeries under regional and local anesthesia [5]. Other factors that determine choice of anesthesia include the proficiency of the anesthetist, patient's preference, surgeons request, duration of the procedure and availability of equipment, lifesaving drugs and anesthetic agents [5]-[7]. In a study, Efu et al [8] demonstrated an overwhelming use of regional/local anesthesia techniques for day case urological surgeries.

This study was conducted to ascertain the anesthetic techniques employed for urological surgeries in the Benue State University Hospital (BSUTH), Makurdi, Nigeria.

\section{METHODOLOGY}

\section{A. Study Design}

This was a three-year retrospective study carried out in BSUTH, Makurdi, a 360-bed hospital situated in the capital city of Benue Sate, North Central Nigeria.

\section{B. Ethical Considerations}

The approval of the BSUTH research and ethical committee was sought and obtained.

\section{Inclusion Criteria}

All urological surgeries carried out in the BSUTH between January 2016 and December 2018 was evaluated.

\section{Exclusion Criteria}

All non-urological surgery cases as well as urological cases whose records were incomplete were excluded.

\section{E. Procedure}

A total of 125 case files of eligible patients were retrieved from the records department of BSUTH after an application to the department was approved. Relevant information was extracted from the patients' folders and transferred into a prepared proforma. The data collected included age, sex, American Society of Anesthesiologists physical status classification (ASA), pre-operative diagnosis, anesthetic technique used, surgical procedure undertaken, whether surgeries were performed as in-patient or day case basis, complications of the anesthetic technique employed and the management of such complication. The data collected were analyzed using SPSS version 25 using simple statistics.

\section{RESULTS}

\section{A. Age distribution}

The age group with the highest number is that between 61 and 70 years, recording $40(32.0 \%)$. This was followed by the age bracket between 51 and 60 years and 71 and 80 years with $23(18.4 \%)$ and $17(14.4 \%)$ respectively. See Fig. 1. The mean age was $54.0 \pm 20.4$.

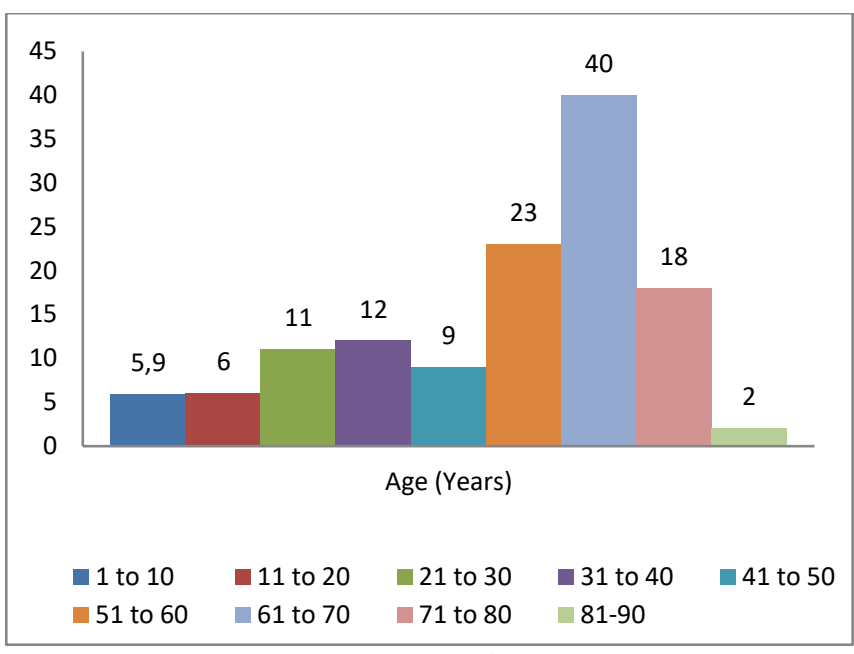

Fig. 1. Histogram showing age of patients $(\mathrm{n}=125)$.

\section{B. Sex distribution}

Males were a majority with 119 cases accounting for $95.2 \%$ while only 6 cases $(4.8 \%)$ involved females. The male to female ratio was 19.8:1.

\section{ASA classification}

Most of the patients belonged to ASA II which recorded $70(56.0 \%)$. This was followed by ASA I and ASA III with $24(19.2 \%)$ and $22(17.6 \%)$ respectively. The rest are as presented in Fig. 2.

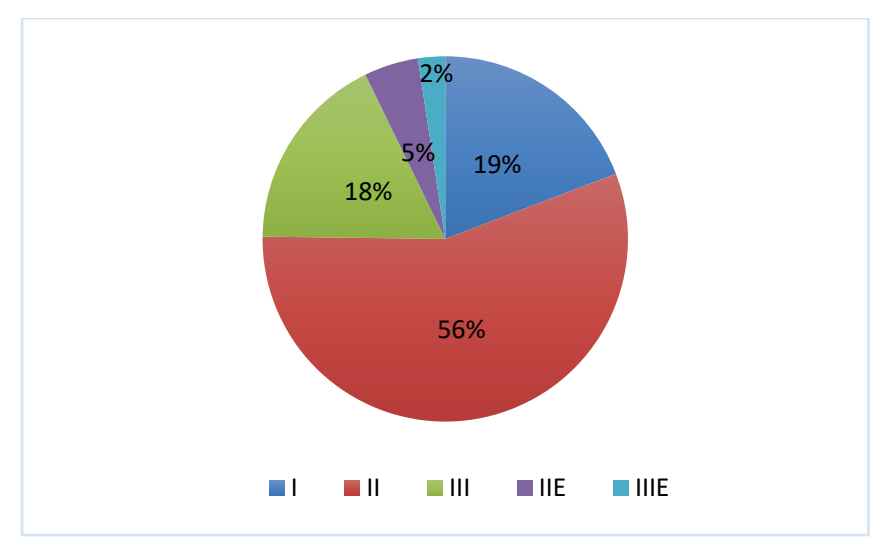

Fig. 2. Pie chart illustrating ASA classification of patients (\%).

\section{Diagnoses}

Of the total of 125 diagnoses made, cancer of the prostate (CaP) was the highest recording 63 (50.4\%). This was followed by benign prostatic hypertrophy (BPH), testicular torsion and urethral stricture recording 14 (11.2\%), 10 $(8.0 \%)$ and $8(6.4 \%)$ respectively. The rest of the diagnoses are as presented on Table 1 .

\section{E. Surgical procedures}

The most common surgical procedure was prostate biopsy which was undertaken 58 times accounting for $46.4 \%$ of the procedures. While orchidectomy and orchidopexy were carried out $10(8.0 \%)$ times each, prostatectomy and urethroplasty took place $9(7.2 \%)$ times each. Other procedures are as presented on Table 2 . 


\begin{tabular}{lcc}
\multicolumn{3}{c}{ TABLE 1: DIAGNOSES } \\
\hline Variable & Frequency $(\mathbf{n = 1 2 5})$ & Percentage $\mathbf{( \% )}$ \\
\hline $\mathrm{CaP}$ & 63 & 50.4 \\
$\mathrm{BPH}$ & 14 & 11.2 \\
Testicular torsion & 10 & 8.0 \\
Urethral stricture & 8 & 6.4 \\
Urinary retention & 4 & 3.2 \\
Nephrolithiasis & 2 & 1.6 \\
Male infertility & 2 & 1.6 \\
Ureteric obstruction & 2 & 1.6 \\
Bladder stones & 2 & 1.6 \\
Others & 18 & 14.4 \\
\hline
\end{tabular}

TABLE 2: SURGICAL PROCEDURES

\begin{tabular}{lcc}
\hline Variable & Frequency $(\mathbf{n = 1 2 5})$ & Percentage $\mathbf{( \% )}$ \\
\hline Prostate biopsy & 58 & 46.4 \\
Orchidectomy & 10 & 8.0 \\
Orchidopexy & 10 & 8.0 \\
Prostatectomy & 9 & 7.2 \\
Urethroplasty & 9 & 7.2 \\
Suprapubic cystostomy & 7 & 5.6 \\
Scrotal exploration & 3 & 2.4 \\
Pyelolithotomy & 2 & 1.6 \\
Testicular biopsy & 2 & 1.6 \\
Pyeloplasty & 2 & 1.6 \\
Cystolithotomy & 2 & 1.6 \\
Others & 11 & 8.8 \\
\hline
\end{tabular}

\section{F. Anesthetic techniques}

Caudal block was employed most recording 59 (47.2\%). This was followed by Local infiltration which recorded 30 (24.0\%). While sub-arachnoid block took place 18 (14.4\%) times, general anesthesia (GA) with endotracheal tube (ETT) was undertaken $12(9.6 \%)$ times. The rest were GA with face mask and GA laryngeal mask airway (LMA) that were undertaken $5(4.0 \%)$ times and once $(0.8 \%)$ (Table. 3$)$.

\begin{tabular}{lcc}
\multicolumn{3}{c}{ TABLE 3: ANESTHETIC TECHNIQUE } \\
\hline Variable & Frequency $(\mathbf{N = 1 2 5})$ & Percentage $\mathbf{( \% )}$ \\
\hline Caudal block & 59 & 47.2 \\
Local infiltration & 30 & 24.0 \\
SAB & 18 & 14.4 \\
GA with ETT & 12 & 9.6 \\
GA with facemask & 5 & 4.0 \\
GA with LMA & 1 & 0.8 \\
\hline
\end{tabular}

\section{G. Mode of admission}

Eighty-eight patients had surgery on day case basis while 37 patients underwent surgery as in-patients representing $70.4 \%$ and $29.6 \%$ of the study group respectively.

\section{H. Complications of anesthetic technique}

There were no complications recorded with the anesthetic techniques employed.

\section{DISCUSSION}

From the result, majority of the patients were old people with the highest number recorded in the age group between 60 and 70 years. A summation of ages 50 years and above made up $83 \%$ of the study population. This can be explained from the point of view that the two most common indications for surgery, cancer of the prostate and benign prostatic hypertrophy which together made up $66.6 \%$ of the diagnoses are diseases that are traditionally seen with advanced age. Ikwuerowo et al. [9] evaluated 1070 patients aged between 7 days and 97 years with children making up $4.5 \%$ and adults making up to $95.5 \%$. In the just cited, even though both pediatric and adult cases were pooled, adults formed a huge majority.

Similarly, the sex distribution is markedly tilted in favour of the male gender because apart from these two diseases, the next most common diseases of torsion tests, urethral stricture and urinary retention are equally diseases seen more with men. A summation of all the diseases highlighted here alone made up $84.2 \%$ of the study population. This agrees with O.A. Swande et al [10] that reported $99 \%$ male population in their own study. Similarly, Ikwuerowo et al [9] found $93.1 \%$ male and $6.9 \%$ female in their study.

Most of the patients belonged to ASA I and II physical status classification with both making up $75.2 \%$ of the study population. This result is in consonance with findings by Efu et al [8] where patients with American Society of Anesthesiologist physical status classification (ASA) I and II made up $84.6 \%$ of the study population. A few ASA III patients were also noted because diseases like metastatic $\mathrm{CaP}$ were also being handled.

With regards to the indications for surgery, it was observed that prostate diseases were the most common. Prostate cancer and benign prostatic hypertrophy together accounted for $66.6 \%$ as stated earlier. This is an indication that the most common reason patients seek surgery is bladder outlet obstruction. This result is in agreement with similar studies by Efu et al. [8] That more cases of cancer of prostate were seen compared to the benign lesions is as a result of late presentation and as patients get older, they tend to develop cancerous lesions more.

On the surgical procedures undertaken, prostate biopsy, orchidectomy and orchidopexy accounted for $62-4 \%$ of the variables. The first two surgical procedures correlate very well with the two most common indications for surgery, i.e. $\mathrm{CaP}$ and $\mathrm{BPH}$. This study is in agreement with findings by Efu et al [8] where prostate biopsy, supra-pubic cystomy and orchidopexy made up $82.7 \%$ of the study group. In their own study, O. A. Sowande et a [10] observed that prostate biopsy, orchidectomy and urethral bouginage constitute $79.3 \%$ of procedures in their study group. Also, Ikuerowo et al [9] reported in their study that both prostate biopsy and orchidectomy made up $40.8 \%$. However, in a similar study conducted by Takure et al [11] the commonest procedure recorded was varicocoelectomy.

Majority of the surgeries were conducted on day case basis $(70.4 \%)$. Anesthetic techniques employed were such that patients would recover sufficiently early enough to return home. Accordingly, caudal block was the used most, followed by local infiltration, both of which make up $71.2 \%$ of the procedures. These two techniques are frequently used for day cases. SAB came next after these two. A summation of caudal block, local infiltration and sub-arachnoid block together made up $85,6 \%$ of the techniques. This result tallies with the study conducted by Efu et al [8] which demonstrated that majority of the procedures were conducted either under regional or local anesthesia with caudal block accounting for $67,3 \%$ of the anesthetic procedures while local infiltration was used for $30.8 \%$ of the cases. In the study by O.A. Sowande et al [10], local anesthetic technique was employed in $81 \%$ of the cases. In 
another study conducted by Takure et al [11], 98.8\% of adults tolerated local anesthesia in form of $0.5 \%$ to $1 \%$ lidocaine with or without adrenaline. Ramyil et al [12] and Amano-Boadu et al [13] also agree that local anesthetic agent (1\% lidocaine injection) is preferred practically in all cases for day case procedure in adults. This is owing to its comparative safety and negligible post-operative problems like nausea, vomiting and headaches, thereby facilitating quicker discharge from hospital.

\section{CONCLUSION}

Urological procedures are mostly infra-umbilical and are thus quite amenable to either regional or local anesthesia. This study has shown that caudal epidural block is the anesthetic technique of choice in urological surgery in this centre. Local anesthesia and sub-arachnoid block are next in that order. GA is not often employed. LA and regional techniques involve fewer disturbances to the respiratory system and these were the anaesthetic methods mostly employed as established in this study.

\section{ACKNOWLEDGMENT}

I wish to register my appreciation to all my co-authors for their huge contributions towards the realization of this publication. Permit me to also thank my office assistants, Dominic Iorhember and Amos Tyosongo for their immeasurable all round support, and in particular, the clerical work of this publication undertaken by them.

\section{REFERENCES}

[1] Duty hours: Neurosurgery. Yale school of medicine. available from: http://www.medicine.yale.edu/neurosurgery/education/tools/duty.aspx [last accessed on 2013 Aug 05].

[2] Kumar S, Toshi MK. Emergency total thyroidectomy for bleeding anaplastic thyroid carcinoma: A viable option for palliation. Indian J Palliat Care 2011; 17:67-9.

[3] Zambouri A. preoperative evaluation and preparation for anaesthesia and surgery. Hippokratia 2007; 11:13-21.

[4] Afolabi BB, Lesi FE. Regional versus general anaesthesia for caesarean section. Cochrane Database Syst Rev. 2012;10:CD004350.

[5] Sharma S. (2019) Anaesthesia for urology in day care. In: Begani M., Mulchandani D., Choudhary S. (eds) Anesthesia in Day Care Surgery, Springer, Singapore.

[6] Obasuyi BI, Alagbe-Briggs OT, Echem RC. Choice of anaesthesia for orthopaedic surgeries in a developing country: How appropriate? J. Med. Sci. 2013; 4: 101- 106.

[7] Nnaji CT, Chekwe K. Anaesthesiafor abdominal myomectomy-A five year. J AnestAnesthes 2017; 1: 16- 19.

[8] Efu ME, Ogwuche EI, Omolabake BI and Eke BA. Anaesthetic techniques in day case urological surgeries in Benue State University Teaching Hospital (BSUTH), Makurdi, Nigeria. Euro. J. Bio and Pharm. Sc. 2019; 6 (10): 95-99.

[9] Ikuerowo SO, Oluwadiya KS, Olapade-olaopa EO, Okeke LI, Shitu OB, Adebayo SA, et al. Caudal block anaesthesia for transrectal prostate biopsy. Int Urol Nephrol, 2010; 42: 19-22.

[10] Sowande OA, Takure AO, Salako AA, Badmus TA, Olajide AO, Banjo OO, Adisa OA. Day Case Urology in a Dedicated Day Case Surgery Unit in a Nigerian Teaching Hospital. J Ambulatory Surgery, 2009; 15(2): 3-11.

[11] Takure AO. Olapade-Olaopa EO, Okeke LI, Adebayo A. Day case urology at Ibadan, Nigeria: A ten year review. Pan Afr Med J, 2010; 6: 13 .

[12] Ramyil VM, Iya D, Ogbonna BC, Dakun NK. Safety of day case hernia repair in Jos Nigeria. East Afr Med J, 2000; 77: 326-8.
[13] Amanor-Boadu SD, Soyannwo OA. Complications following day case paediatric surgery. West Afr J Med, 1997; 16: 223-6. 